\title{
Isolation and Characterization of a Cold-Tolerant Strain of Fusarium proliferatum, a Biocontrol Agent of Grape Downy Mildew
}

\author{
Shlomo Bakshi, Abraham Sztejnberg, and Oded Yarden
}

First, second, and third authors: Department of Plant Pathology and Microbiology, Faculty of Agricultural, Food and Environmental Quality Sciences, The Hebrew University of Jerusalem, Rehovot 76100, Israel; and third author: The Otto Warburg Center for Agricultural Biotechnology, The Hebrew University of Jerusalem, Rehovot 76100, Israel.

Accepted for publication 17 July 2001.

\begin{abstract}
Bakshi, S., Sztejnberg, A., and Yarden, O. 2001. Isolation and characterization of a cold-tolerant strain of Fusarium proliferatum, a biocontrol agent of grape downy mildew. Phytopathology 91:1062-1068.

A cold-tolerant strain of the mycoparasite Fusarium proliferatum was isolated following UV mutagenesis of the G6 strain, which is a biocontrol agent of grape downy mildew. The isolated strain (designated 1505) exhibited radial growth two to threefold that of the parent strain when grown at $13^{\circ} \mathrm{C}$, which is generally suboptimal for growth of Fusarium spp., but desirable for its host, Plasmopara viticola. This rapid growth

at higher temperatures was slower than that of G6 and the strain failed to conidiate, there was no reduction in biocontrol efficacy. Significantly higher levels of extracellular $\beta$-glucosidase and endo-1,4- $\beta$-glucanase activity were measured in the culture filtrate of strain 1505 relative to that of strain G6. A DNA-mediated transformation procedure that included the introduction of antibiotic resistance and a GUS reporter gene system was adapted for $F$. proliferatum. Using the GUS-engineered strains, we demonstrated that both G6 and 1505 exhibit the characteristic coiling and penetration of host structures.
\end{abstract} was correlated with improved biological control of $P$. viticola, determined by a detached-leaf assay. Even though radial growth of strain 1505
Additional keyword: cellulase.
Grape downy mildew disease, inflicted by Plasmopara viticola (Berk. \& M.A. Curtis) Berl. \& De Toni in Sacc., causes severe damage on the grape clusters and reduction in yield $(1,32)$. Fusarium proliferatum (T. Matsushima) Nirenberg (teleomorph Giberella fujikuroi [Sawada] Ito in Ito \& K. Kimura) is a unique biocontrol agent of grape downy mildew disease and potentially of other Oomycotina plant pathogens $(15,16)$. In preliminary tests (A. Sztejnberg, unpublished data), F. proliferatum G6 (the biocontrol agent) was not pathogenic to a number of plants infected by $F$. proliferatum and closely related Fusarium spp. (14,22,29,38,39). Nevertheless, there was some interest in improving the isolate's performance under different environmental conditions. One such desirable trait is antagonistic capacity at low temperatures, because $P$. viticola is capable of surviving and reproducing at relatively low temperatures $\left(13\right.$ to $\left.18^{\circ} \mathrm{C}\right)(26)$. Wong et al. (40) demonstrated the use of cold-tolerant isolates of Gaeumannomyces graminis var. graminis and Phialophora spp. to control take-all disease of wheat in Australia. In addition, results of studies on growth and antagonism-linked attributes of cold-tolerant isolates of Metarhizium and Trichoderma spp. have indicated that such strains have a potential of being harnessed for use in biological control $(2,10)$. Such strains can be obtained by screening natural isolates or by mutagenesis. UV mutagenesis has yielded different phenotypes in Fusarium spp. $(25,41)$.

The cell walls of Oomycotina, among them $P$. viticola, contain $\beta$-glucans, cellulose (a homopolymer of $1,4-\beta$-glucan), and relatively small amounts of chitin $(<1.5 \%)$. One means by which mycoparasites penetrate the host cell wall is by secreting hydrolytic enzymes that can degrade these cell wall components. Enzymatic degradation of fungal cell walls occurs mainly via the excretion of

Corresponding author: A. Sztejnberg; E-mail address: abraham@agri.huji.ac.il

Publication no. P-2001-0830-02R

(C) 2001 The American Phytopathological Society extracellular enzymes (7), and the presence of such enzymes has been demonstrated in several mycoparasites $(13,28,33)$.

Trichoderma spp. attack pathogens by excreting lytic enzymes, including glucanases, chitinases, proteases, and lipases, that enable them to degrade host cell walls and thus reduce disease incidence (20). Kubicek et al. (24) reviewed the cellulase system of Trichoderma spp., which consists of three general classes of enzymes: (i) 1,4- $\beta$-D-glucan cellobiohydrolases ( $\mathrm{CBH}$, EC 3.2.1.91), which cleave cellobiosyl units from the nonreducing end of cellulose chains; (ii) endo-1,4- $\beta$-D-glucanases [EG, cellulase: $1,3-(1,3 ; 1,4)-$ $\beta$-D-glucan 3(4) glucanohydrolase, EC 3.2.1.4], which cleave internal glucosidic bonds; and (iii) 1,4- $\beta$-D-glucosidase (cellobiase; $\beta$-D-glucoside glucohydrolase, EC 3.2.1.21), which cleaves cello-oligosaccharides to produce glucose.

The molecular analysis of $F$. proliferatum as a biocontrol agent is in its infancy. The involvement of lytic enzymes (such as demonstrated for Trichoderma) is yet unknown, and a DNAmediated transformation system, which could be instrumental for introducing new traits (such as reporter genes) or for strain improvement, has not been developed for this species.

In this paper, we report on the isolation of a cold-tolerant strain derived from the mycoparasite $F$. proliferatum isolate G6 following UV mutagenesis. We determined the activity and abundance of extracellular glucanolytic enzymes in isolates G6 and the cold-tolerant mutant, and report on a modification of the protoplast-based method for DNA-mediated transformation of $F$. proliferatum.

\section{MATERIALS AND METHODS}

Fungal strains and plant material. $F$. proliferatum was isolated from atypical grape downy mildew lesions on Vitis vinifera L. 'Chardonnay' in Suffolk County, NY, during the summer of 1991 (15). The single-spore isolate G6 was maintained on potato dextrose agar (PDA; Difco Laboratories, Sparks, MD) at 25 to $28^{\circ} \mathrm{C}$. 
$P$. viticola was isolated from leaves of $V$. vinifera $\mathrm{cv}$. Sultanine in Rehovot, Israel, in 1995, and cultured at weekly intervals by spraying a suspension of sporangia washed from sporulating lesions onto detached leaves from potted grapevines (cv. Sultanine). Inoculated leaves were placed inside growth chambers in which high humidity was maintained by the constant presence of moist filter paper along the chamber bottom and walls. Suspensions of $P$. viticola sporangia were prepared for leaf infection by washing sporangia off sporulating lesions on leaves with deionized water applied with a hand-held sprayer. The collected sporangial suspensions were counted in a hemacytometer and adjusted to a concentration of $10^{5}$ sporangia per $\mathrm{ml}$. The suspensions were kept at $23^{\circ} \mathrm{C}$ for $1 \mathrm{~h}$ to allow the sporangia to release zoospores before application to leaves. After $24 \mathrm{~h}$ of incubation (postinoculation), the leaves were blotted with absorbent tissue paper. The leaves were transferred to petri dishes that were subsequently sealed with Parafilm and transferred to a growth chamber set at $25^{\circ} \mathrm{C}$ and a 12-h photoperiod.

Determining the optimal growth temperature of fungal isolates. To determine the optimal growth temperature of isolate G6, disks (6-mm diameter) of 6-day-old cultures grown on PDA were transferred to the center of new petri dishes with PDA and incubated at different temperatures. The colony area was measured every $24 \mathrm{~h}$. These experiments were repeated five times.

To determine the optimal growth temperature of $P$. viticola, inverted leaves were arranged on moistened filter paper (Whatman No. 3, Maidstone, England) in glass petri dishes (9-cm diameter and $2 \mathrm{~cm} \mathrm{high).} \mathrm{Each} \mathrm{leaf} \mathrm{was} \mathrm{divided} \mathrm{into} \mathrm{five} \mathrm{fragments.} \mathrm{The}$ underside of each leaf fragment was inoculated at three points with drops ( $20 \mu \mathrm{l}$ each) of a suspension of zoospore-releasing $P$. viticola sporangia $\left(10^{5}\right.$ sporangia per $\left.\mathrm{ml}\right)$. Petri dishes containing the inoculated fragments (representing three different leaves) were subsequently incubated at different temperatures. After $24 \mathrm{~h}$ of incubation, the leaves were blotted with absorbent tissue paper. The dishes were sealed with Parafilm and incubated at different temperatures with a 12-h photoperiod at a radiation intensity of $60 \mu \mathrm{mol} / \mathrm{m}^{2} / \mathrm{s}$. Production of $P$. viticola sporangia was quantified 9 days later. Three $P$. viticola lesions were removed from each leaf and washed with $\leq 0.5 \mathrm{ml}$ of deionized water with an aerosol sprayer (Preval; Precision Valve Corporation, Yonkers, NY). The total number of sporangia per lesion was calculated by examining the suspension with a hemacytometer. The experiment was repeated three times.

UV irradiation mutagenesis. Microconidia of isolate G6 grown on PDA were collected with water by flooding the petri dish. Mycelial suspensions were subsequently filtered through a double layer of surgical gauze. Aliquots $(4 \mathrm{ml})$ of a $10^{5}$ conidia per $\mathrm{ml}$ conidial suspension were transferred to 5-cm-diameter petri dishes. Immediately thereafter, open petri dishes were exposed to various periods of 254-nm UV radiation (Spectrolinker XL-1000 UV crosslinker; Spectronics Corporation, Westbury, NY) at a distance of $15 \mathrm{~cm}$ from the radiation source. Mutant screens were carried out on populations from the surviving $10 \%$ following the UV treatment.

Mycoparasitism assays. Inverted leaves were arranged on moistened filter paper in glass petri dishes (9-cm diameter and $2 \mathrm{~cm}$ high). The underside of each leaf was inoculated with 3 drops $(20 \mu \mathrm{l}$ each) of a suspension of zoospore-releasing $P$. viticola sporangia $\left(10^{5}\right.$ sporangia per $\left.\mathrm{ml}\right)$. After $24 \mathrm{~h}$ of incubation, the leaves were inserted for $1 \mathrm{~min}$ into a sodium hypochlorite $(\mathrm{NaOCl})$ solution $(1 \%, \mathrm{wt} / \mathrm{wt})$, washed thoroughly with water, and blotted with absorbent tissue paper. The dishes were sealed with Parafilm and transferred to a growth chamber set at $25^{\circ} \mathrm{C}$ and a 12-h photoperiod. Sporulation of $P$. viticola was first observed 4 days after inoculation. Five days after inoculation with $P$. viticola, $F$. proliferatum was applied by spraying a suspension of microconidia $\left(10^{6}\right.$ microconidia per $\left.\mathrm{ml}\right)$ with an aerosol sprayer onto the underside of the leaves. The droplets were allowed to dry, and the dishes were resealed and returned to the growth chamber for 7 to 9 days. Assays were repeated five times.

Qualitative analysis of extracellular glucanolytic enzymes of F. proliferatum. For extracellular protein concentration measurements, isolate G6 conidia were adjusted to a density of $10^{6}$ in $25 \mathrm{ml}$ of Czapek (11) synthetic medium in 100-ml Erlenmeyer flasks and cultured on an orbital shaker $(120 \mathrm{rpm})$ at $28^{\circ} \mathrm{C}$ for 5 days. Growth media were filtered through Whatman No. 1 filter paper and centrifuged at $3,500 \times g$ for $10 \mathrm{~min}$ at $4^{\circ} \mathrm{C}$. Proteinase inhibitors (Complete; Boehringer Mannheim GmbH, Mannheim, Germany) were added to the culture fluid. Additional filtration through a $0.22-\mu \mathrm{m}$ membrane was performed on ice. The mycelia were dried for $48 \mathrm{~h}$ at $60^{\circ} \mathrm{C}$ and weighed. Protein quantification was determined by the Bradford protocol (6). Glucanolytic enzymes were detected with a set of two highly sensitive substrates that produce a fluorescent product (4-methylumbelliferyl) following enzymatic hydrolysis: (i) 4-methylumbelliferyl- $\beta$-D-glucoside [4-MU-(Glu)], and (ii) 4-methylumbelliferyl- $\beta$-D-cellotrioside [4-MU-(Glu) $)_{3}$ (both from Sigma Chemical Co., St. Louis). These compounds function as dimeric and tetrameric substrates, respectively, with the 4-MU group linked by $1,4-\beta$ linkage to the glucan oligosaccharides. Enzyme activity was detected by adding $100 \mu \mathrm{l}$ of culture fluid to $10 \mu \mathrm{l}$ of the substrate reagent (prepared as a stock solution of $1.5 \mathrm{mg}$ of substrate in $5 \mathrm{ml}$ of $0.5 \mathrm{M}$ potassium-acetate buffer, $\mathrm{pH}$ 5.0) predispensed in 96-well microtiter dishes and incubated at $37^{\circ} \mathrm{C}$ for 10 to $120 \mathrm{~min}$. Glucanolytic activity was identified by the presence of the fluorescent product, observed under a UV light source. These experiments were repeated five times, with protein extracts prepared from independently grown cultures.

DNA-mediated transformation and reporter gene expression. Plasmid pGPD-GUS (23) was used for transformation of $F$. proliferatum. pGPD-GUS is a pBluescript-based plasmid containing the bacterial hygromycin phosphotransferase gene ( $h p h)$ under the control of the Aspergillus niger Pgla promoter and $\operatorname{TrpC}$ terminator, and the $\beta$-glucuronidase (GUS) reporter gene under the control of the Cochliobolus heterostrophus Pgpd promoter and NOS terminator. Our transformation procedure was a modified form of that developed for $C$. heterostrophus (37). Twenty-twohour old mycelium suspensions of isolate G6 (originating from $10^{6}$ conidia grown in $100 \mathrm{ml}$ of PDA) were digested in the presence of $0.7 \mathrm{M} \mathrm{NaCl}, 10 \mathrm{mg}$ of glucanase (Novo Nordisk, Bagsværd, Denmark) per $\mathrm{ml}, 10 \mathrm{mg}$ of Driselase (Kyowa Hakko, Kogyo, Japan) per $\mathrm{ml}$, and $0.05 \mathrm{mg}$ of Streptomyces griseus chitinase (Sigma Chemical) per $\mathrm{ml}$ for approximately $2 \mathrm{~h}\left(30^{\circ} \mathrm{C}, 70 \mathrm{rpm}\right)$. Protoplasts were separated by centrifugation $(2,500 \times g$ for $15 \mathrm{~min})$,

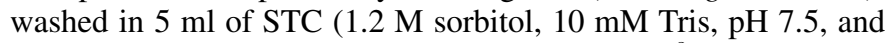
$50 \mathrm{mM} \mathrm{CaCl}_{2}$ ), and adjusted to a cell density of $10^{8}$ protoplasts per milliliter of STC, and subsequently dispensed as 100- $\mu$ l aliquots. Plasmid DNA (pGPD-GUS) transformations were performed on ice, and wide-bore pipette tips were used for all phases. The predispensed protoplast aliquots were placed in 15-ml plastic conical tubes. A total of $25 \mu \mathrm{g}$ of DNA was added to the protoplasts, and the tubes were carefully inverted several times and incubated on ice for $10 \mathrm{~min}$. A solution of $60 \%$ polyethylene glycol (molecular weight of 3,500 to 4,000) in $10 \mathrm{mM}$ Tris, $\mathrm{pH}$ 7.5 , and $50 \mathrm{mM} \mathrm{CaCl}_{2}$ was added in three consecutive aliquots of 200, 200, and $800 \mu \mathrm{l}$. The tube contents were mixed after the addition of each aliquot and incubated on ice for $20 \mathrm{~min}$. The protoplasts were diluted with $1 \mathrm{ml}$ of STC and carefully mixed.

Following transformation, $200 \mu \mathrm{l}$ of the reaction mixture was mixed with $20 \mathrm{ml}$ of molten regeneration medium consisting of PDA plus $20 \%$ (wt/vol) sucrose (maintained at $45^{\circ} \mathrm{C}$ ). After $4 \mathrm{~h}$, the plates were overlaid with $10 \mathrm{ml}$ of molten regeneration medium containing $150 \mu \mathrm{g}$ of hygromycin B (Boehringer Mannheim $\mathrm{GmbH}$ ) per $\mathrm{ml}$. The petri dishes were sealed with Parafilm, inverted, and incubated at $28^{\circ} \mathrm{C}$. The transformed, hygromycinresistant transformants grew through the selective medium within 3 to 7 days. 
The reagent for the visualization of GUS reporter gene activity contained $1 \mathrm{mM}$ 5-bromo-4-chloro-3-indolyl- $\beta$-D-glucuronic acid (X-Gluc; Inalco, Milano, Italy) dissolved in $N, N$-dimethylformamide (Sigma) and mixed with $0.1 \mathrm{M} \mathrm{NaPO}_{4}(\mathrm{pH} 7.0), 10 \mathrm{mM}$ EDTA, $0.5 \mathrm{mM}$ each of potassium ferricyanide $\left(\mathrm{K}_{3} \mathrm{Fe}(\mathrm{CN})_{6}\right)$ and potassium ferrocyanide $\left(\mathrm{K}_{4} \mathrm{Fe}(\mathrm{CN})_{6} 3 \mathrm{H}_{2} \mathrm{O}\right)$ (Sigma), and $0.1 \%$ (vol/vol) Triton X (Sigma). The samples were incubated overnight at $37^{\circ} \mathrm{C}$.

For Southern blot hybridization analysis of transformants, mycelial samples were collected by filtration on Whatman No. 1 filter paper over a Büchner funnel. Samples were quick-frozen in liquid nitrogen and lyophilized. DNA was extracted from the dry samples as described by Beth-Din and Yarden (5). DNA manipulation (digestion with restriction enzymes, Southern blot analyses) was performed as described by Sambrook et al. (35). A 2-kb SalI fragment derived from pGPD-GUS plasmid that encodes the GUS gene was separated electrophoretically and excised from an agarose gel. The fragment was labeled with $\left[\alpha-{ }^{32} \mathrm{P}\right] \mathrm{dCTP}$ (Amersham International, Little Chalfont, England) using a random-priming labeling kit (Prime-a-Gene; Promega, Madison, WI) in a total volume of $50 \mu \mathrm{l}$. Unincorporated nucleotides were removed by chromatography on a Sephadex G-50 column (Pharmacia Biotech, Uppsala, Sweden). Blotting and detection were performed as described by Sambrook et al. (35).

Visualization of GUS expression during $F$. proliferatum G6 parasitism of $\boldsymbol{P}$. viticola. Expression of the GUS gene during $F$. proliferatum parasitism of $P$. viticola on leaves was determined as follows: tissue samples were incubated with the reagent mix for 2 to $5 \mathrm{~h}$ at $37^{\circ} \mathrm{C}$, and cleared of chlorophyll by adding a drop of lactophenol (45\% glycerol, 27\% lactic acid, and 28\% liquefied phenol, all vol/vol) and heating for a few seconds over an open flame. Unless stated otherwise, the tissue samples were immobilized on commercial scotch tape by applying gentle pressure on the tape after it had been placed on the samples. The immobilized samples were incubated with the reagent mix for 2 to $5 \mathrm{~h}$ at $37^{\circ} \mathrm{C}$. Samples were then examined by light microscopy (Axioscop; Zeiss, Oberkochen, Germany). Similar observations were repeatedly (five times) obtained with several GUS transformants parasitizing $P$. viticola on leaves.

\section{RESULTS}

Isolation of a G6-derived mutant with improved radial growth at low temperatures. We used UV irradiation to create mutations in the G6 isolate and screened the mutants for improved

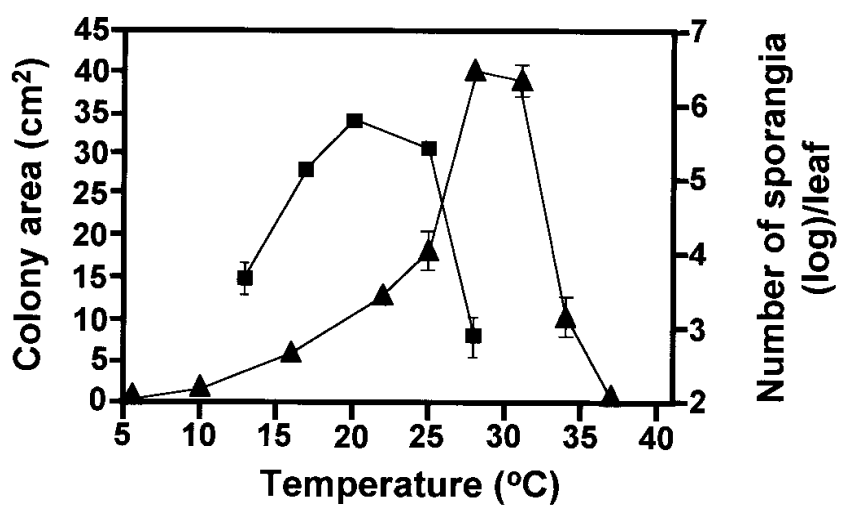

Fig. 1. Temperature growth curves of Fusarium proliferatum G6 (A) and Plasmopara viticola (-) isolates. Growth of the $F$. proliferatum G6 isolate on potato dextrose agar at different temperatures after 7 days of incubation was determined by colony area. The results represent the average of five replicates and are accompanied by standard error bars. The growth of $P$. viticola was assessed by sporangia production on leaves at different temperatures after 10 days of incubation. The results represent the average of three replicates (each replicate contained three $P$. viticola lesions) and are accompanied by standard error bars. radial growth at low temperatures. Based on measurements of radial hyphal growth, we determined the optimal growth temperature of isolate $\mathrm{G} 6$ to be approximately $28^{\circ} \mathrm{C}$ (Fig. 1). At the lower temperatures of 13 to $20^{\circ} \mathrm{C}$, at which $P$. viticola reproduces well (Fig. 1), G6 grows very slowly. Populations consisting of the $10 \%$ that had survived the UV treatment were plated at low densities on PDA and transferred to $17^{\circ} \mathrm{C}$. The radial growth rates of different isolates growing at $17^{\circ} \mathrm{C}$ were compared with that of the G6 strain at different temperatures by placing 6-mm-diameter disks of colonized PDA in the center of PDA dishes and recording colony area over time. Five fast-growing colonies were identified and isolated. Among the five isolates, only one (designated 1505) maintained a consistent and uniform fast-growing phenotype under low temperature conditions. The other four isolates gradually lost this ability and developed new slow growing sectors exhibiting growth rates similar to that of isolate G6. Following 10 days of incubation, the colony area of isolate 1505 was two to three times larger than that of isolate G6 at low temperatures (13 and $\left.17^{\circ} \mathrm{C}\right)$. However, isolate 1505 exhibited a significantly slower growth rate (approximately 50\%) at the higher temperatures determined to be optimal for G6 growth (Fig. 2). Although strain 1505 hyphal and colony morphology appeared to be normal, this isolate failed to conidiate. All treatments used in attempt to induce the production of conidia in this strain-exposure to sunlight, UV radiation, use of a variety of poor and rich growth media, and cyclic AMP amendment to the culture medium - failed. Thus, even though a mutant capable of growing aster at low temperatures was produced, the slower growth at elevated temperatures and the inability to conidiate under the conditions tested suggested that several genes had been affected during the mutagenesis process.

Strain 1505, an effective broad temperature spectrum mycoparasite. Mycoparasitism tests were performed to uncover any detrimental changes in the mycoparasitic properties of isolate 1505. P. viticola-infected leaves were prepared as described previously. However, because strain 1505 did not produce conidia, a $F$. proliferatum hyphal disk was used as a substitute for the mycoparasitic conidial suspension. Five days after inoculation, disks (5-mm diameter) of isolate 1505, prepared from 2- to 3-week-old cultures grown on PDA at $17^{\circ} \mathrm{C}$, were placed at a distance of $2 \mathrm{~mm}$ from each $P$. viticola lesion. Disks of the G6 isolate (prepared from 2- to 3-week-old cultures grown on PDA at 25 to $28^{\circ} \mathrm{C}$ ) were used as controls. The dishes were resealed and returned to the growth chamber at either 13 or $25^{\circ} \mathrm{C}$ and a $12-\mathrm{h}$ photoperiod with a radiation intensity of $60 \mu \mathrm{mol} / \mathrm{m}^{2} / \mathrm{s}$. Treatments were replicated five times at each temperature.

Initial observations provided a clear indication of the occurrence of a mycoparasitic interaction between isolate 1505 and $P$.

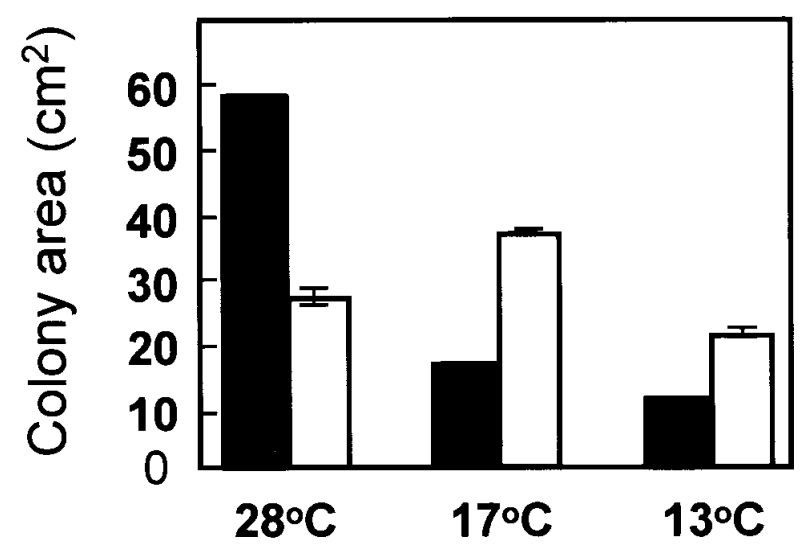

Fig. 2. Hyphal growth of isolates G6 and 1505 (black and white columns, respectively) of Fusarium proliferatum on potato dextrose agar at different temperatures after 10 days of incubation. The results represent the average of five replicates and are accompanied by standard error bars. 
viticola. Thus, although strain 1505 was defective in its conidiating capacity and grew slower at high temperatures, the capacity to infect its host was not lost during the mutagenesis process, and at low temperatures, coverage of the $P$. viticola colonies by isolate 1505 was significantly broader than that of isolate G6 (Fig. 3).

To assess the quantitative extent of mycoparasitism, additional similar experiments were performed. Production of $P$. viticola sporangia was quantified 9 days later. Three $P$. viticola lesions were removed from each leaf and washed with $\leq 0.5 \mathrm{ml}$ of distilled water (applied with an aerosol sprayer). The total number of sporangia per lesion was calculated by examining the suspension with a hemacytometer. At $25^{\circ} \mathrm{C}$, disks of both isolates 1505 and G6 reduced production of sporangia by $85 \%$ compared with lesions that were not treated with the mycoparasite (Fig. 4). When grown at $13^{\circ} \mathrm{C}$, isolate 1505 reduced sporangial production by $85 \%$, whereas treatment with isolate G6 reduced their production by only $35 \%$ (Fig. 4).

Qualitative analysis of extracellular glucanolytic enzymes of $\boldsymbol{F}$. proliferatum. To improve the uniformity and induce near-synchronous growth, three disks (6-mm diameter each) of nonconidiating isolate 1505 were transferred to $25 \mathrm{ml}$ of Czapek media in $100-\mathrm{ml}$ Erlenmeyer flasks. The flasks were shaken at $120 \mathrm{rpm}$ at $28^{\circ} \mathrm{C}$ for 5 days. The mycelial suspensions were macerated (10-min maceration, 10-min cooling interval, and 10-min maceration), sieved through surgical gauze, and adjusted to a density of $10^{6}$ mycelial fragments in fresh Czapek medium $(25 \mathrm{ml}$ in a 100 -ml Erlenmeyer flask). After 5 days of additional incubation $\left(120 \mathrm{rpm}\right.$ at $\left.28^{\circ} \mathrm{C}\right)$, the cultures were filtered and the protein concentration in the culture fluids was determined. In repeated experiments, we consistently observed a twofold higher extracellular protein concentration ( 45 to $55 \mu \mathrm{g} / \mathrm{ml}$ ) in the culture filtrate of isolate 1505, relative to that measured in the G6 filtrate, even though a similar mass ( 0.9 to $1 \mathrm{~g}$ dry weight per $25 \mathrm{ml}$ of culture) was produced by both isolates during the 5-day growth period. Following the incubation of identical amounts of culture filtrate proteins at $37^{\circ} \mathrm{C}$ for 10 to $120 \mathrm{~min}$ with glucanolytic enzymesensitive substrates, specific activities of $1,4-\beta$-glucosidases in the culture filtrate of isolate 1505 were markedly higher than those in the G6 culture filtrate (Fig. 5).

The presence of fluorescent products in the 1505 filtrate-treated dimer substrate before that of the G6 filtrate indicated higher 1,4$\beta$-glucosidases activity in the culture fluid of the former. That fluorescent products were present in the 1505 filtrate-treated, but not present in the G6 filtrate-treated tetramer substrate wells, suggests higher activity of endo-1,4- $\beta$-D-glucanases, which cleave internal glucosidic bonds, in the strain 1505 filtrate. A similar tendency was observed when the fungi were cultured at $13^{\circ} \mathrm{C}$ and incubated with the same substrates at 13 or $37^{\circ} \mathrm{C}$ and when the fungi were grown at $25^{\circ} \mathrm{C}$ and culture filtrates were incubated at 25 or $37^{\circ} \mathrm{C}$ (data not shown), indicating that this phenomenon is not affected by incubation temperature.

DNA-mediated transformation and reporter gene expression. To provide a convenient tool for following the $F$. proliferatum parasite on its host, a protoplast-based DNA transformation protocol was used to transform isolate G6 of $F$. proliferatum and confer resistance to hygromycin $\mathrm{B}$. Prior to developing the protocol, dose-response curves of hygromycin B toxicity were obtained to determine the concentration at which mycelial growth was totally inhibited. Based on the results obtained (data not shown), a concentration of $150 \mu \mathrm{g}$ of hygromycin B per ml was chosen for the selection procedure. The Escherichia coli $\beta$-Dglucuronidase (GUS) reporter gene has been successfully used as a genetic marker for the transformation of Fusarium spp. $(9,12)$. To date, there has been no reported genetic transformation of $F$. proliferatum.

Following transformation with the pGPD-GUS plasmid, 48 hygromycin-resistant transformants were initially analyzed for GUS expression. Of these, $48 \%$ expressed the GUS reporter gene, upon analysis in the GUS activity reagent mix.

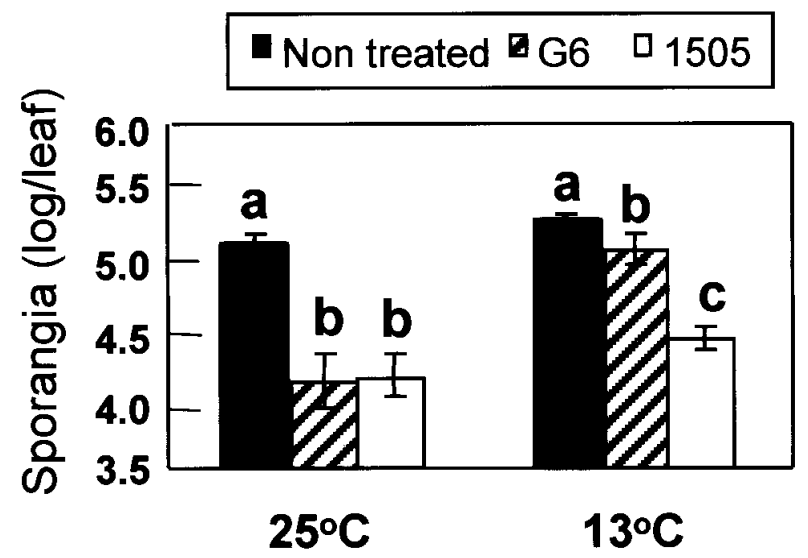

Fig. 4. Plasmopara viticola sporangia production in the presence or absence of the G6 or 1505 strains of Fusarium proliferatum at near-optimal $\left(25^{\circ} \mathrm{C}\right)$ and suboptimal $\left(13^{\circ} \mathrm{C}\right)$ temperatures for $\mathrm{G} 6$ growth. The results represent the average of five replicates and are accompanied by standard error bars. Within a temperature regime, different letters indicate a significant $(P=0.01)$ difference between the $F$. proliferatum treatments.
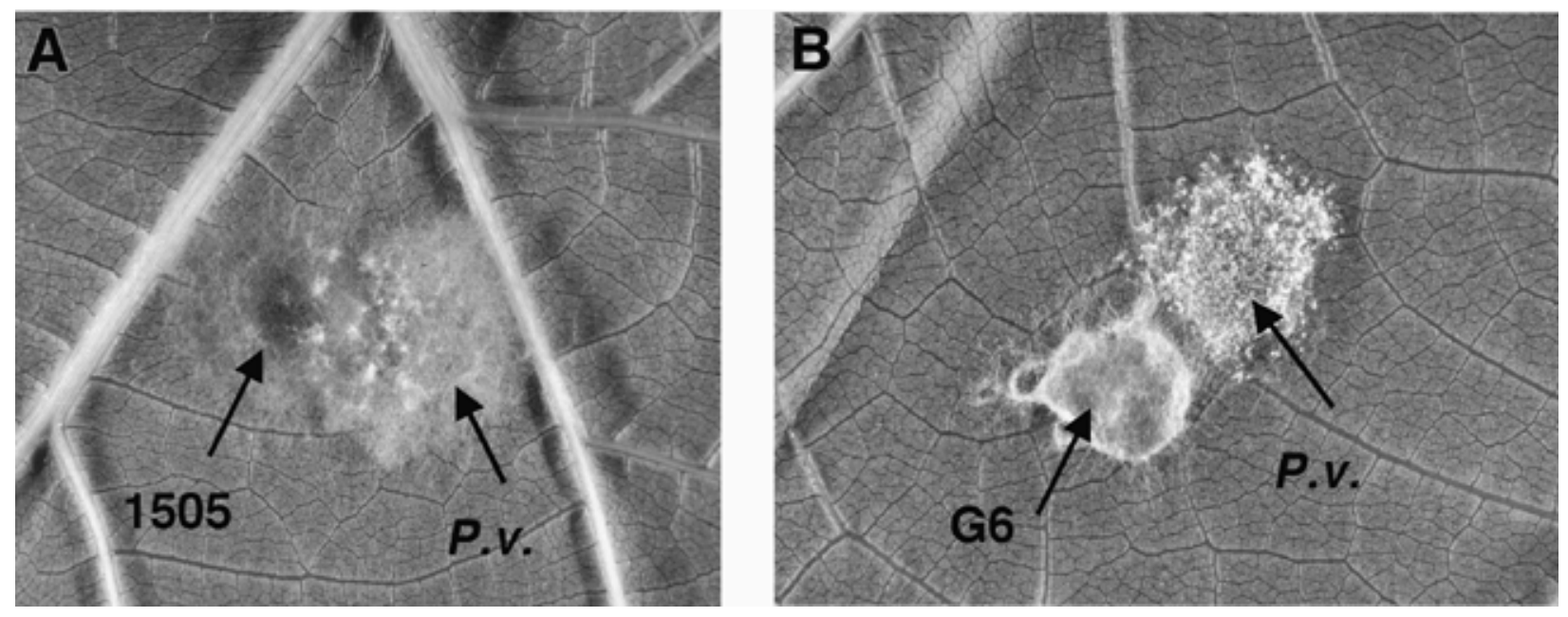

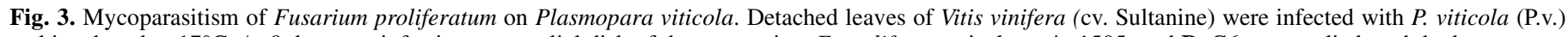

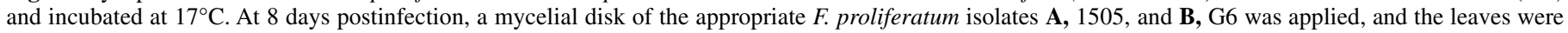
incubated for an additional 5 days. 
The stability of GUS expression was maintained following several conidial transfers. The transformants were also stable after a 2-month storage period (in the presence of $50 \%$ glycerol) at $-80^{\circ} \mathrm{C}$. The presence of the pGPD-GUS DNA in transformants was verified by Southern blot analysis of transformant genomic DNA (data not shown).

DNA-mediated transformation and reporter gene expression in $\boldsymbol{F}$. proliferatum isolate 1505. Because the basis for $F$. proliferatum protoplast preparation was germinating conidia and strain 1505 did not produce conidia, we adapted a method described by Royer and Yamashiro (34) for the generation of transformation-competent protoplasts from mycelia. To obtain myceliaderived protoplasts, isolate 1505 was grown in potato dextrose broth (PDB) and macerated as described previously. The mycelial fragments were transferred to new flasks and cultured for an additional 5 days under the same conditions. The mycelial suspensions were macerated again, collected, and adjusted to a density of $10^{7}$ mycelial fragments in $100 \mathrm{ml}$ of fresh PDB in 250-ml Erlenmeyer flasks. Enzymatic digestion, protoplast isolation, transformation, and transformant selection were as described for germinating conidia. Fifteen strain 1505 hygromycin-resistant transformants were originally obtained. Ten of the transformants expressed the GUS reporter gene upon transfer to the reagent mix. These transformants were stable after 2 months of storage at $-80^{\circ} \mathrm{C}$ (although they were maintained as mycelial fragments, and not conidia as described for the G6 isolate).

Visualization of GUS expression during $F$. proliferatum parasitism on $\boldsymbol{P}$. viticola. Lesions were sprayed with microconidia of $F$. proliferatum G6 transformant (designated 27). After 7 days, the samples were prepared for visualization and the mycoparasite proliferation was observed by microscopy. Based on the expression of GUS in the $F$. proliferatum hyphae, it was easy to identify their characteristic coiling around $P$. viticola sporangiophores (Fig. 6A). Blue hyphae were observed within sporangiophores and even within sporangia (Fig. 6B and C). These results support earlier scanning and transmission electron microscope studies (15). However, this is the first time hyphae of $F$. proliferatum have been identified within sporangia of $P$. viticola. Thus, the use of a reporter gene appears to provide an additional option for studying fungal-fungal interactions, especially when similar hyphal structures may impose difficulties in analyzing the data obtained by electron microscopy.

In parallel, we followed parasitism of strain 1505, utilizing the GUS reporter gene system. Because this strain does not conidiate, one disk of transformant 27 (with an isolate 1505 background), from 2- to 3-week-old cultures grown on PDA at $28^{\circ} \mathrm{C}$, was

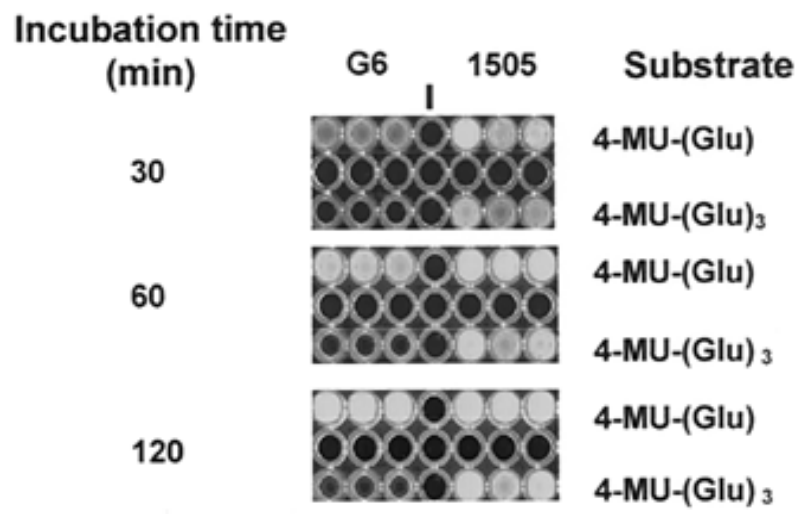

Fig. 5. Detection of glucanolytic activity, using the 4-methylumbelliferyl- $\beta$ D-glucoside dimer [4-MU-(Glu)] and the 4-methylumbelliferyl- $\beta$-D-cellotrioside tetramer [4-MU-(Glu $)_{3}$ ] substrates. Fluorescent products, indicative of substrate cleavage, were observed under a UV light source, at different time points, following the addition of equal amounts of protein from either G6 or 1505 strain culture filtrates. placed beside each $P$. viticola lesion. Visualization of GUS expression was performed as described with the G6 isolate, and parasitism of strain 1505 on $P$. viticola was observed (Fig. 6D).

\section{DISCUSSION}

The occurrence of resistant pathotypes, along with the environmental concerns accompanying the use of chemicals for disease control in a variety of crops, has increased interest in the utilization of potential biocontrol agents for disease control. Grapes are a prime example of a crop that is highly sensitive to a broad range of diseases, yet are subject to increasingly strict regulations concerning pesticide use. The commercial potential of a mycoparasitic biocontrol agent, Ampelomyces quisqualis, for the control of powdery mildews has already been demonstrated (8). Reports on another potential biocontrol agent of downy mildew (another significant disease of grape) have been published (16). Because biocontrol agents are of a less eradicative nature than successful antifungal, chemical-based treatments, optimization of biocontrol agent characteristics can play a significant role in the control strategy. Based on the measurement of $P$. viticola sporangial production and the radial hyphal growth of $F$. proliferatum G6, we determined their optimal growth temperatures (20 and $28^{\circ} \mathrm{C}$, respectively). This is in good agreement with optimal growth temperatures described by Lalancette et al. (27) for $P$. viticola and by Wagih et al. (39) for another isolate of $F$. proliferatum. In this paper, we describe the isolation of a $F$. proliferatum strain that exhibits increased tolerance to growth inhibition at lower temperatures, without compromising its ability to parasitize $P$. viticola. The screen used to obtain strain 1505 was based on UV mutagenesis and as such was exposed to the pros and cons of this procedure. Thus, a desired phenotype was obtained in a positive selection protocol, although the genes conferring this desirable trait are not yet available (in this or any other organism). In fact, even though significant advances have been made in analyzing the molecular basis for cold tolerance in plants (19), there are only a few reports on cold tolerance in fungi $(2,10,17,36,40)$. Furthermore, introduction of foreign DNA was not required, a factor that may prove to be crucial at a time when public concerns regarding the use of transgenic organisms prevail $(4,18,21)$. Nonetheless, the shortcomings of the UV (or other) mutagenesis

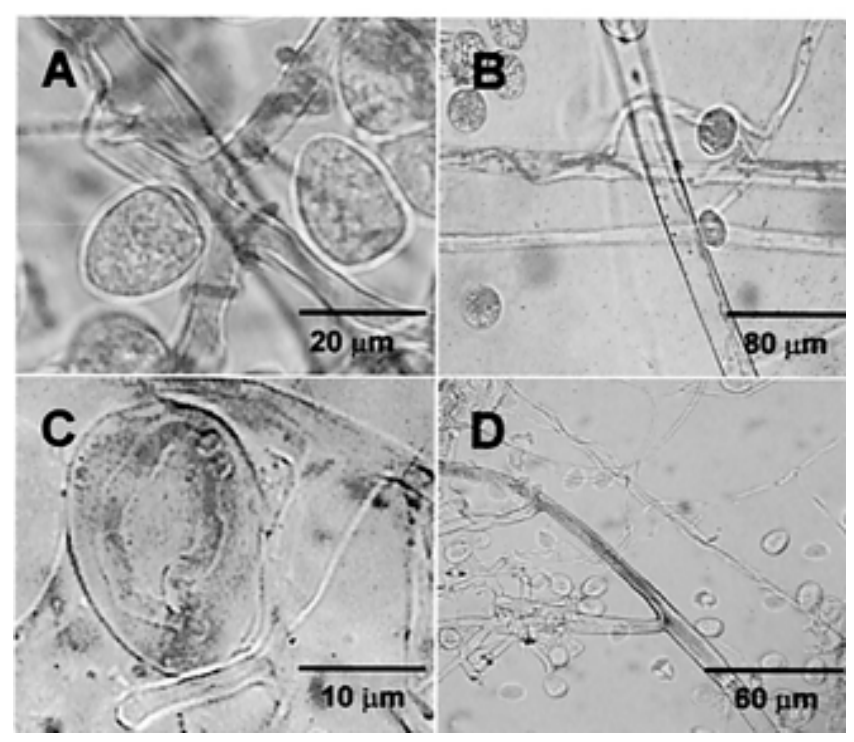

Fig. 6. Visualization of GUS-expressing Fusarium proliferatum G6 and 1505 during parasitism on Plasmopara viticola. A, Hyphae of F. proliferatum G6, transformant 27, coiled around a sporangiophore of $P$. viticola. B, $F$. proliferatum G6 hyphae growing within a sporangiophore of $P$. viticola. $\mathbf{C}$, Detection of $F$. proliferatum G6 hyphae within a sporangium of $P$. viticola. D, F. proliferatum 1505 parasitizing $P$. viticola. 
approach, some of which are exemplified in this report, should be addressed. It is quite likely that strain 1505 was mutated in more than one gene, evidenced by the pleiotropic phenotype obtained. It is conceivable that cold tolerance, conidiation, and increased secretion of proteins (including glucanolytic enzymes) to the medium are not regulated by a single gene product. Whether these different genes reside within the same chromosomal locus (in which case, the pleiotropic effect could be the result of a relatively large deletion or rearrangement event), or the effect is due to multiple, physically unrelated mutational events, has yet to be resolved. This can be approached by either classical genetics-via crossing and progeny analysis as described by Yan and Dickman (41) — or by complementation studies, utilizing (as yet unavailable) genomic libraries. The ability of isolate 1505 to suppress the number of sporangia produced by the $P$. viticola host (by $85 \%$ ) at $25^{\circ} \mathrm{C}$ was similar to that of the parent G6 isolate. This result was surprising because isolate 1505 grew slower (on PDA) at $25^{\circ} \mathrm{C}$, the optimal growth temperature of G6. We, therefore, concluded that the antagonistic activity of isolate 1505 was not impaired by the mutagenesis procedure. Furthermore, at low temperature $\left(13^{\circ} \mathrm{C}\right)$ the antagonistic activity of isolate 1505 (as determined by the number of sporangia released by the host) was significantly enhanced when compared with the efficacy of the G6 isolate.

Because the cell walls of Oomycotina, among them $P$. viticola, contain cellulose, we compared the activity levels of extracellular cellulolytic enzymes in the culture filtrate of isolate G6 with those in isolate 1505 culture. In filtrates of 5-day-old cultures grown at $28^{\circ} \mathrm{C}$, isolate 1505 secreted approximately twofold the amount of proteins secreted by isolate G6. The activity of glucanolytic enzymes was tested by monitoring the release of fluorescent product liberated from the 4-MU-modified dimer and tetramer glycoside substrates. This method has also been used by Barth and Bridge (3), who demonstrated a difference in the activity of extracellular 1,4- $\beta$-glucosidases of $F$. oxysporum $\mathrm{f}$. sp. lycopersici when compared with $F$. oxysporum f. sp. vasinfectum and other fungi. When treated with culture fluid containing equal quantities of extracellular proteins, it was clear that the accumulation of dimer hydrolysis product was faster when the substrate was treated with culture fluid of isolate 1505 (Fig. 5). This could be the result of either a specific change in the activity of one or more $1,4-\beta$-glucosidases due to the mutagenic process, or a change in the relative or absolute abundance of the secreted glucosidases. In addition to the enhanced activity demonstrated by the hydrolysis of the dimer substrate, we observed that the G6 filtrate almost completely lacked the capacity to hydrolyze the tetramer substrate. This indicates that the 1505 mutant secretes a detectable level of endo-1,4- $\beta$ glucanases. The twofold increase in total secreted proteins measured in the 1505 filtrate is unlikely to be entirely and specifically attributable to glucosidases. Thus, we believe a more general change in protein production/secretion occurred in strain 1505 . The potential occurrence of a general change in protein secretion is further supported by results of a series of experiments in which the fungi were cultured at either low $\left(13^{\circ} \mathrm{C}\right)$ or high $\left(37^{\circ} \mathrm{C}\right)$ temperatures and the enzymatic reactions were also performed at different temperatures $\left(25\right.$ or $\left.37^{\circ} \mathrm{C}\right)$, all of which provided evidence that the difference in enzymatic activity was not temperature-dependent (data not shown), in contrast to growth. The link between the increased levels of secreted proteins, the involvement of glucosidases, and successful mycoparasitism of isolate 1505 has yet to be determined.

To advance the practical potential for analysis of $F$. proliferatum as a fungus, as well as the interactions between various $F$. proliferatum strains and $P$. viticola, we adapted a protoplast-based DNA-mediated transformation protocol for $F$. proliferatum and showed that antibiotic resistance and reporter gene expression can be conferred to this organism. In terms of the transformation frequencies obtained, we were able to transform $F$. proliferatum in a manner similar to that obtained in other Fusarium spp. $(9,30,31)$.
The availability of such protocols, along with the production of additional tools for molecular analysis, will assist in addressing fundamental questions concerning the pleiotropic nature of strain 1505, along with practical approaches rendering this strain's utilization (alone or in combination with others) for biological control. We believe that a combination of classical and molecular techniques is a rational and rewarding approach to the enhancement of biocontrol agent performance.

\section{ACKNOWLEDGMENTS}

We thank B. Cohen and U. Yechye for their suggestions and assistance during the course of this study.

\section{LITERATURE CITED}

1. Agrios, G. N. 1997. Plant Pathology. 4th ed. Academic Press, San Diego, CA.

2. Antal, Z., Manczinger, L., Szakacs, G., Tengerdy, R. P., and Ferenczy, L. 2000. Colony growth, in vitro antagonism and secretion of extracellular enzymes in cold-tolerant strains of Trichoderma species. Mycol. Res. 104:545-549.

3. Barth, M. G. M., and Bridge, P. D. 1989. 4-Methylumbelliferyl substituted compounds as fluorogenic substrates for extracellular enzymes. Lett. Appl. Microbiol. 9:177-179.

4. Beachy, R. N. 1999. Facing fear of biotechnology. Science 285:335.

5. Beth-Din, A., and Yarden, O. 1994. The Neurospora crassa chs-2 gene encodes a non-essential chitin synthase. Microbiology 140:2189-2197.

6. Bradford, M. M. 1976. A rapid and sensitive method for the quantitation of microgram quantities of protein utilizing the principle of protein-dye binding. Anal. Biochem. 72:248-254.

7. Chet, I., Inbar, J., and Hadar, Y. 1997. Fungal antagonists and mycoparasitism. Pages 165-184 in: The Mycota. Vol. 4. D. T. Wicklow and B. E. Soderstorm, eds. Springer-Verlag, Berlin.

8. Copping, L. G. 1998. The Biopesticide Manual: World Compendium. 1st ed. British Crop Protection Council, Farnham, U.K.

9. Couteaudier, Y., Daboussi, M. J., Eparvier, A., Langin, T., and Orcival, J. 1993. The GUS gene fusion system (Escherichia coli $\beta$-D-glucuronidase gene), a useful tool in studies of root colonization by Fusarium oxysporum. Appl. Environ. Microbiol. 59:1767-1773.

10. De Croos, J. N. A., and Bidochka, M. J. 1999. The effects of low temperature on growth parameters in the entomopathogenic fungus Metarhizium anisopliae. Can. J. Microbiol. 45:1055-1061.

11. Dhingra, O. D., and Sinclair, J. B. 1986. Basic Plant Pathology Methods. CRC Press, Boca Raton, FL.

12. Doohan, F. M., Smith, P., Parry, D. W., and Nicholson, P. 1998. Transformation of Fusarium culmorum with the $\beta$-D-glucuronidase (GUS) reporter gene: A system for studying host-pathogen relationships and disease control. Physiol. Mol. Plant Pathol. 53:253-268.

13. Elad, Y., Chet, I., Boyle, P., and Henis, Y. 1983. Parasitism of Trichoderma spp. on Rhizoctonia solani and Sclerotium rolfsii-scanning electron microscopy and fluorescence microscopy. Phytopathology 73:85-88.

14. Elmer, W. H. 1990. Fusarium proliferatum as a causal agent in Fusarium crown and root rot of asparagus. Plant Dis. 74:938.

15. Falk, S. P., Pearson, R. C., Gadoury, D. M., Seem, R. C., and Sztejnberg, A. 1996. Fusarium proliferatum as a biocontrol agent against grape downy mildew. Phytopathology 86:1010-1017.

16. Falk, S. P., Pearson, R. C., Gadoury, D. M., and Sztejnberg, A. 1995. Biological control of grape downy mildew by Fusarium proliferatum. (Abstr.) Phytopathology 85:1147.

17. Feofilova, E. P., Tereshina, V. M., Memorskaya, A. S., Zav, Y. L. A., and Maryshova, N. S. 1999. Changes in the cytosol carbohydrate composition during the cytodifferentiation process in fungi of the order Agaricales. Microbiology 68:356-361.

18. Frank, L. 2000. Consumer power heralds hard times for researchers. Science 287:790-791.

19. Guy, C. 1999. Molecular responses of plants to cold shock and cold acclimation. J. Mol. Microbiol. Biotechnol. 1:231-242.

20. Haran, S., Schickler, H., and Chet, I. 1996. Molecular mechanisms of lytic enzymes involved in the biocontrol activity of Trichoderma harzianum. Microbiology 142:2321-2331.

21. Haslberger, A. G. 2000. Monitoring and labeling for genetically modified products. Science 287:431-432.

22. James, R. L., Dumroese, R. K., and Wenny, D. L. 1995. Fusarium proliferatum is a common, aggressive pathogen of container-grown conifer seedlings. (Abstr.) Phytopathology 85:1129. 
23. Khan, R., and Straney, D. C. 1999. Regulatory signals influencing expression of the PDA1 gene of Nectria haematococca MPVI in culture and during pathogenesis of pea. Mol. Plant-Microbe Interact. 12:733742 .

24. Kubicek, C. P., Messner, R., Gruber, F., Mach, R. L., and Kubicek Pranz, E. M. 1993. The Trichoderma cellulase regulatory puzzle: From the interior life of a secretory fungus. Enzyme Microb. Technol. 15:90-99.

25. Kuhad, R. C., Kumar, M., and Singh, A. 1994. A hypercellulolytic mutant of Fusarium oxysporum. Lett. Appl. Microbiol. 19:397-400.

26. Lafon, R., and Bulit, J. 1981. Downy mildew of the vine. Pages 601-614 in: The Downy Mildews. D. M. Spencer, ed. Academic Press, London.

27. Lalancette, N., Madden, L. V., and Ellis, M. A. 1988. A quantitative model for describing the sporulation of Plasmopara viticola on grape leaves. Phytopathology 78:1316-1321.

28. Larena, I., and Melgarejo, P. 1993. The lytic enzymatic complex of Penicillium purpurogenum and its effects on Monilinia laxa. Mycol. Res. 97:105-110.

29. Logrieco, A., Moretti, A., Ritieni, A., Bottalico, A., and Corda, P. 1995. Occurrence and toxigenicity of Fusarium proliferatum from preharvest maize ear rot, and associated mycotoxins, in Italy. Plant Dis. 79:727-731.

30. Malardier, L., Daboussi, M. J., Julien, J., Roussel, F., Scazzocchio, C., and Brygoo, Y. 1989. Cloning of the nitrate reductase gene (niaD) of Aspergillus nidulans and its use for the transformation of Fusarium oxysporum. Gene 78:147-156.

31. Marek, E. T., Schardl, C. L., and Smith, D. A. 1989. Molecular transformation of Fusarium solani with an antibiotic resistance marker having no fungal DNA homology. Curr. Genet. 15:421-428.

32. Pearson, R. C., and Goheen, A. C. 1988. Compendium of Grape
Diseases. The American Phytopathological Society, St. Paul, MN.

33. Rotem, Y., Yarden, O., and Sztejnberg, A. 1999. The mycoparasite Ampelomyces quisqualis expresses exgA encoding an exo- $\beta$-1,3-glucanase in culture and during mycoparasitism. Phytopathology 89:631-638.

34. Royer, J. C., and Yamashiro, C. T. 1992. Generation of transformable spheroplasts from mycelia, macroconidia, microconidia and germinating ascospores of Neurospora crassa. Fungal Genet. Newsl. 39:76-79.

35. Sambrook, J., Fritsch, E. F., and Maniatis, T. 1989. Molecular Cloning: A Laboratory Manual. Cold Spring Harbor Laboratory, Cold Spring Harbor, NY.

36. Sterflinger, K. 1998. Temperature and NaCl-tolerance of rock-inhabiting meristematic fungi. Antonie Leeuwenhoek 74:271-281.

37. Turgeon, B. G., Garber, R. C., and Yoder, O. C. 1985. Transformation of the fungal maize pathogen Cochliobolus heterostrophus using the Aspergillus nidulans amdS gene. Mol. Gen. Genet. 201:450-453.

38. Viljoen, A., Wingfield, M. J., Marasas, W. F. O., and Coutinho, T. A. 1995. Characterization of Fusarium isolates from gladiolus corms pathogenic to pines. Plant Dis. 79:1240-1244.

39. Wagih, E. E., Shehata, M. R. A., Farag, S. A., and Dawood, M. K. 1989. Dracaena leaf proliferosis, a newly recorded disease affecting Dracaena sanderiana in Egypt. J. Phytopathol. 126:7-16.

40. Wong, P. T. W., Mead, J. A., and Holley, M. P. 1996. Enhanced field control of wheat take-all using cold tolerant isolates of Gaeumannomyces graminis var. graminis and Phialophora sp. (loped hyphophia). Plant Pathol. 45:285-293.

41. Yan, K., and Dickman, M. B. 1996. Isolation of a beta-tubulin gene from Fusarium moniliforme that confers cold-sensitive benomyl resistance. Appl. Environ. Microbiol. 62:3053-3056. 